\title{
Optimum Cooling Based on the Exit Openings Position for Turbulent Mixed Convection in Ventilated Cavities
}

\author{
Mohamed Chaour ${ }^{*}$, Saadoun Boudebous², Abdelkader Filali ${ }^{3,4}$ \\ ${ }^{1}$ Department of Mechanical Engineering, University of Brothers Mentouri, 25017 Constantine, 325 Ain El Bey Way, Algeria \\ 2 Department of Mechanical Engineering, University of Larbi Ben M'hidi, 04000 Oum El Bouaghi, P. O. B. 358, Algeria \\ ${ }^{3}$ Department of Mechanical Engineering, Ecole Nationale Polytechnique de Constantine, Nouvelle Ville Ali Mendjli, \\ 25000 Constantine, P. O. B. 75, Algeria \\ ${ }^{4}$ Department of Chemical Engineering, Imperial College London, SW7 2AZ London, Imperial College Rd., United Kingdom \\ * Corresponding author, e-mail: chaourmed@yahoo.fr
}

Received: 17 March 2020, Accepted: 04 September 2020, Published online: 05 October 2020

\begin{abstract}
In this paper, turbulent mixed convection in a ventilated square cavity exposed to a cooling of the blocks is studied numerically. The cavity walls were kept adiabatic except the right vertical wall which was equipped with three blocks dissipating the heat at a constant temperature. The commercial Ansys Fluent code is used and governing equations were established and discretized by the finite volume method. The standard $k-\varepsilon$ model is considered for the turbulence modeling and SIMPLE algorithm is used for the pressure velocity coupling. The objective of the present study is to characterize the best outlet location that provides the greatest effective cooling in the blocks by maximizing the heat-elimination rate and decreasing the total temperature in the cavity. Obtained results showed that the variations of the air outlet position in the cavity and the Richardson number have major effects on the stream function and heat transfer.
\end{abstract}

\section{Keywords}

turbulent mixed convection, vented square cavity, varied outlet location, cooling internal blocks, finite volume method

\section{Introduction}

The use of the mixed convection phenomenon to design efficient ventilation schemes is one of the high-impact solutions, which has received considerable attention during the last few decades. These ventilation arrangements are present in various areas of engineering such as: ventilation of buildings [1], solar collectors [2], air conditioning equipment [3] and many applications related to the cooling of electronic systems [4-6]. The effectiveness of electronic equipment is extremely dependent on the efficiency of the cooling and stacking of components. Arrangement of components is a very popular feature in electronic equipment housed in a cabinet. Several authors have taken into account mixed convection in ventilated enclosures [7-12]. Convection in cavity containing blocks has gained recent research consequence as a means of heat transfer improvement [13-17]. Hence, many researchers have investigated the properties of this problem in a vast range of situations.

Numerical simulations of the turbulent mixed convection in ventilation systems is carried by means of different turbulence models, either relying on Reynolds-averaged Navier-Stokes equations (RANS) [3], low-Reynolds $k$ - $\varepsilon$ model $[6,8,18-20]$, or RANS models such as the RNG $k-\varepsilon$ and the SST $k$ - $\omega$ model $[2,3,7]$, and even the Large Eddy Simulation (LES) [21-23] model. However, nowadays standard k- $\varepsilon$ model are most often used [24-29], as the last method (LES) require too much computational resources. For example, Costa et al. [19] performed detailed numerical study of mixed convection airflow in a ventilated chamber in which eight different versions of low-Reynolds $k$ - $\varepsilon$ turbulence models were considered for comparison with experimental data. Results showed that the turbulent models were dependent on the performance of the examined problem and particularly sensitive to the location of unstable thermal stratification.

Investigation of turbulent mixed convection in a ventilated system was carried by several authors which can be pointed out and summarized hereafter. Koufi et al. [20] investigated numerically the heat transfer by turbulent 
mixed convection inside ventilated cavities with supply and exhaust slots. Four different configurations were considered, and the bottom of the cavity was maintained at a constant hot temperature $T H$, while the other walls are fixed at a cold temperature $T C$. Results were analyzed in terms of the ventilation efficiency and the influence of heating on the flow and thermal behavior for different Rayleigh numbers ranging from $6.4 \times 10^{8}$ to $3.2 \times 10^{9}$. Results showed that the configuration $\mathrm{D}$ with an inlet at the top and the outlet at the bottom of the left vertical wall provides a better ventilation effectiveness. Later, a numerical study was performed by Doghmi et al. [17] to analyze the heat transfer by mixed convection in an isothermal heating source inside a three-dimensional ventilated cavity with different inlet and outlet locations using the finite volume method. The results are presented in terms of flow structures, temperature distribution and mean Nusselt number for various combinations of thermal control parameters, namely, Reynolds number $(50 \leq \mathrm{Re} \leq 100)$ and number of Richardson $(0 \leq \mathrm{Ri} \leq 10)$. The obtained results showed that the intensity of the flux and the rate of heat transfer can be considerably improved by an optimal choice of the parameters mentioned for different inlet and outlet locations. Mamun et al. [13] conducted a numerical study of mixed convection heat transfer within a ventilated square cavity contained a heated hollow cylinder. The cavity walls were considered adiabatic and the heated blank cylinder was placed at the middle of the cavity. Streams were executed through the inlet at the bottom of the left wall and the outlet at the upper of the right wall of the cavity. Importance about the influence of the disk diameter and the thermal conductivity of the disk on the heat transfer in a ventilated cavity are investigated. Results showed that the best heat transfer could be obtained for the largest cylinder diameter and the lowest thermal conductivity value. Ezzouhri et al. [21] carried out three-dimensional numerical simulation of turbulent mixed convection in ventilated cavity with inlet and outlet apertures under thermal stratification. Numerical results obtained using Large Eddy Simulation (LES) are compared with experimental data. The LES model proved its efficiency and good accuracy in comparison with existing experimental data. Huang et al. [23] presented experimental and numerical investigations of the turbulent mixed convection in a cavity for a range of large Rayleigh number to further investigate the effect of the buoyancy effects. The LES model is used and the turbulence quantities such as temperature and velocity fluctuations, and turbulent heat flux were found highly concentrated near the heated aspect walls and the center jet boundary. LES results were compared successfully with experimental data. In addition, Tian and Karayiannis [30] presented experimental investigations of the turbulent natural convection in a cavity. The left and right vertical walls of the cavity were at constant temperature of 50 and $10^{\circ} \mathrm{C}$, respectively, while the remaining walls are considered adiabatic. Results showed low turbulent levels at the flow exist and the flow is limited in a narrow strip along the walls where the velocity and temperature change sharply. Very recently, SerranoArellano et al. [31] performed a numerical analysis of heat and mass transfer in a ventilated cavity in a warm climate area. The equations of the mathematical model were solved by the finite volume method and the $k-\varepsilon$ turbulence model is used to find the results of the variables of interest in seven climate records for a given day. The inlet flow velocity of the air- $\mathrm{H}_{2} \mathrm{O}$ mixture has been changed by the Reynolds number from 500 to 10,000. The findings allowed for a better understanding of the behavior of air flow with water vapor as well as the concentration of chemical species inside a ventilated room, which will give new solutions to create better hygrothermal conditions in a building. Also, Kriraa et al. [32] carried out numerical investigation for the convection of water in a chemical condenser having two openings located along one side of the cavity. Governing equations were solved based finite volume method and the SIMPLEC algorithm was selected for the coupling of the pressure and velocity. Particular attention was paid to the influence of Reynolds number, channel inclination and Rayleigh number on convective heat transfer. The results were presented and discussed to cover a relatively wide intervals; $10^{4} \leq \mathrm{Ra} \leq 5 \times 10^{5}$, $10 \leq \operatorname{Re} \leq 1000$ and the inclination of the channel $0^{\circ} \leq \varphi \leq 90^{\circ}$. Based on these results, a new correlation of the Nusselt number was developed.

Based on the above-mentioned studies, we can state that no previous numerical study is available on the turbulent mixed convection in ventilated cavities fitted out with heating blocks and with different exit opening positions. This is why, in the present study, numerical simulation of turbulent mixed convection in two-dimensional ventilated square enclosure containing three heating blocks at constant temperature $T_{H}$ placed in the right wall is investigated. All remaining walls of the cavity were considered adiabatic. The flow was imposed through the inlet at the bottom of the left wall. The aim of the present investigation is to find the precise location of the flow exit 
in order to obtain the most efficient and effective mean to ensure the optimal cooling of such systems, which can be help engineers and designers in that specific area.

\section{Problem definitions}

Fig. 1 presents the different geometries of the considered problem. The computational domain is a ventilated square enclosure with a side length $H=1 \mathrm{~m}$. Three heating blocks at constant temperature $T_{H}=308 \mathrm{~K}$ were placed and centered on the right vertical wall. All remaining walls of the enclosure were assumed to be adiabatic. The inlet and exit sections have the same dimension $h=0.1 \mathrm{H}$ and the inlet air has a temperature $T c=288 \mathrm{~K}$. The length, the thickness of the fins and the distance between them were denoted by $d=0.2 \mathrm{H}, d w=0.05 \mathrm{H}$ and $w=0.2 \mathrm{H}$, respectively. The inlet was placed at the bottom of the left vertical wall. For the outlet, five configurations were examined:

- (A) Outlet on the upper part of the right wall,

- (B) Outlet on the right part of the upper wall,

- (C) Outlet at the center of the upper wall,

- (D) Outlet on the left side of the upper wall

- and (E) Outlet on the upper side of the left wall.

\section{Mathematical models}

Fluid flow and heat transfer are demonstrated in a two-dimensional vented square enclosure turbulent. The fluid is assumed Newtonian and incompressible. All thermo physical properties of the fluid are supposed constant except the density which is calculated based on the Boussinesq approximation (buoyancy forces). The standard $k-\varepsilon$ model is selected for the turbulence modeling. Governing equations for turbulent mixed convection flow is described mathematically by Reynolds averaged Navier-Stokes equations (RANS). The equations describing the flow can be formed as follows [33]:

- Continuity equation:

$$
\frac{\partial u}{\partial x}+\frac{\partial v}{\partial y}=0
$$

- Momentum equation in $x$-direction:

$$
\begin{aligned}
& \frac{\partial u}{\partial t}+u \frac{\partial u}{\partial x}+v \frac{\partial u}{\partial y}=-\frac{1}{\rho} \frac{\partial p}{\partial x}+\frac{\partial}{\partial x}\left[\left(v+v_{t}\right)\left(\frac{\partial u}{\partial x}\right)\right] \\
& +\frac{\partial}{\partial y}\left[\left(v+v_{t}\right)\left(\frac{\partial u}{\partial y}\right)\right],
\end{aligned}
$$

- Momentum equation in $y$-direction:

$$
\begin{aligned}
& \frac{\partial v}{\partial t}+u \frac{\partial v}{\partial x}+v \frac{\partial v}{\partial y}=-\frac{1}{\rho} \frac{\partial p}{\partial y}+\frac{\partial}{\partial y}\left[\left(v+v_{t}\right)\left(\frac{\partial v}{\partial x}\right)\right] \\
& +\frac{\partial}{\partial y}\left[\left(v+v_{t}\right)\left(\frac{\partial v}{\partial y}\right)\right]+g \beta\left(T-T_{C}\right),
\end{aligned}
$$

- Energy equation:

$$
\begin{aligned}
& \frac{\partial T}{\partial t}+u \frac{\partial T}{\partial x}+v \frac{\partial T}{\partial y}=\frac{\partial}{\partial x}\left[\left(\alpha+\frac{v_{t}}{\operatorname{Pr}_{t}}\right)\left(\frac{\partial T}{\partial x}\right)\right] \\
& +\frac{\partial}{\partial y}\left[\left(\alpha+\frac{v_{t}}{\operatorname{Pr}_{t}}\right)\left(\frac{\partial T}{\partial y}\right)\right],
\end{aligned}
$$

- Turbulent kinetic energy equation:

$$
\begin{aligned}
& \frac{\partial k}{\partial t}+u \frac{\partial k}{\partial x}+v \frac{\partial k}{\partial y}=\frac{\partial}{\partial x}\left[\left(v+\frac{v_{t}}{\sigma_{k}}\right) \frac{\partial k}{\partial x}\right] \\
& +\frac{\partial}{\partial y}\left[\left(v+\frac{v_{t}}{\sigma_{k}}\right) \frac{\partial k}{\partial y}\right]+G_{k}+G_{b}-\varepsilon,
\end{aligned}
$$

- Turbulent kinetic energy dissipation rate equation:

$$
\begin{aligned}
& \frac{\partial \varepsilon}{\partial t}+u \frac{\partial \varepsilon}{\partial x}+v \frac{\partial \varepsilon}{\partial y}=\frac{\partial}{\partial x}\left[\left(v+\frac{v_{t}}{\sigma_{\varepsilon}}\right) \frac{\partial \varepsilon}{\partial x}\right] \\
& +\frac{\partial}{\partial y}\left[\left(v+\frac{v_{t}}{\sigma_{\varepsilon}}\right) \frac{\partial \varepsilon}{\partial y}\right]+C_{1 \varepsilon} \frac{\varepsilon}{k}\left(G_{k}+C_{3 \varepsilon} G_{b}\right)-C_{2 \varepsilon} \frac{\varepsilon^{2}}{k},
\end{aligned}
$$

where

$$
\begin{aligned}
& G_{k}=\tau_{\text {turb }} \frac{\partial u_{j}}{\partial x_{i}}, G_{b}=-\frac{g \beta v_{t}}{\operatorname{Pr}_{t}} \frac{\partial T}{\partial y} \text { and } v_{t}=C_{\mu} \frac{k^{2}}{\varepsilon} \\
& C_{1 \varepsilon}=1.44, C_{2 \varepsilon}=1.92, C_{3 \varepsilon}=\tanh (v / u), C_{\mu}=0.09, \\
& \sigma_{k}=1.0, \sigma_{\varepsilon}=1.3 .
\end{aligned}
$$
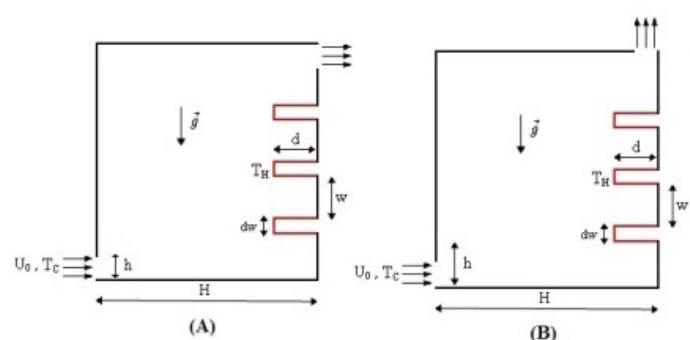

(B)
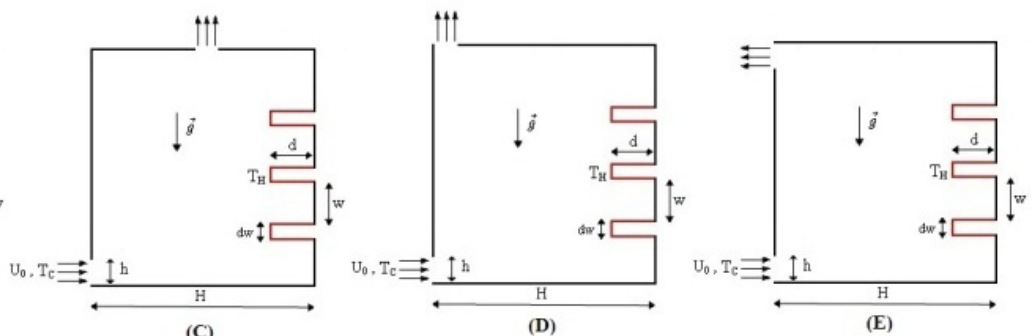

Fig. 1 Schematic of the various configurations 
The heat transfer through the hot blocks is evaluated by the average Nusselt number:

$\mathrm{Nu}=-\frac{1}{L_{h}} \int_{0}^{L_{h}} \frac{\partial T}{\partial n} \times \partial n_{T}$,

where $L_{h}$ is the total length of the upper, lower and thickness sides of the blocks. The integral giving the average Nusselt number (Eq. (7)) it discretized and calculated by the Simpson's method in [34].

In the above equations, the variables of dimensions are defined by:

$\operatorname{Pr}=\frac{v}{\alpha} ; \mathrm{Gr}=\frac{g \times \beta\left(T_{H}-T_{C}\right) H^{3}}{v^{2}} ; \mathrm{Ri}=\frac{G_{r}}{R_{e}^{2}} ; \mathrm{Re}=u_{0} \frac{H}{v}$.

\section{Numerical method}

Governing equations were discretized by the finite volume method used by the commercial code FLUENT. A second-order upwind scheme is selected for discretizing the convection terms and a central scheme for the diffusive terms. SIMPLE algorithm is also adopted for pressure-velocity coupling calculations.

In the present study, a grid sensitivity test is performed for the mesh independent solution and the tested meshes and results are presented in Table 1 for $\mathrm{Ri}=1$ and $\mathrm{Pr}=0.7$. Results show that the grids $(300 \times 400$ to $500 \times 600)$ do not produce any significant differences in the calculated average Nusselt number. Hence a non-uniform grid of $400 \times 500$ with larger concentration of grid points near the blocks is adopted for all presented computations in the present paper.

As a first step, to validate the computer code and mathematical model, a comparison between the present work and the results obtained by Tian and Karayiannis [30] is performed. The comparison is carried out for the case of turbulent natural convection in a cavity with heated left vertical wall at a constant temperature and cooled right vertical wall at a constant temperature. Remaining

Table 1 Comparison of the average Nusselt number for different grid sizes at $\mathrm{Pr}=0.7$ and $\mathrm{Ri}=1$ in the case $(\mathrm{A})$

\begin{tabular}{lccc}
\hline $\begin{array}{l}\mathrm{N}^{\circ} \text { of } \\
\text { grid }\end{array}$ & Mesh size & Average Nusselt number & Relative Error (\%) \\
\hline 1 & $200 \times 300$ & 25.63995 & 31.51 \\
2 & $300 \times 400$ & 34.1463 & 8.79 \\
3 & $400 \times 500$ & 36.01378 & 3.80 \\
4 & $500 \times 600$ & 37.43728 & - \\
\hline
\end{tabular}

walls are considered adiabatic. The average Nusselt numbers on the hot wall were calculated and compared with Rayleigh number, $\mathrm{Ra}=1.58 \times 10^{9}$. The comparison shows that the maximum difference of the average Nusselt number reached about $5 \%$ as shown in Table 2 .

In order to validate the numerical approach of the present study, a second comparison is performed by comparing the temperature profile on the mid height location as shown in Fig. 2. This comparison showed a satisfactory agreement between the results obtained in this work and those of Tian and Karayiannis [30], which gives us comfort in the reliability of the present numerical approach.

\section{Results and discussion}

Present results for the turbulent air flow having a constant Prandtl number $(\mathrm{Pr}=0.7)$ are investigated for different geometrical cases with the variation of the outlet position. Grashof number is considered constant $\left(\mathrm{Gr}=3.18 \times 10^{9}\right)$. As recalled recently by Mokeddem et al. [35], it is generally accepted that the natural convection is negligible when $\mathrm{Ri}<<1$, forced convection is negligible when $\mathrm{Ri} \gg 1$. The flow regimes in between these two limits are mixed convection regime. Consequently, we have presented results for $\mathrm{Ri}=0.2$ (forced convection-dominated regime), $\mathrm{Ri}=5$ (natural convection-dominated regime) and $\mathrm{Ri}=1$ (mixed convection regime). So the appropriate values of the Reynolds number are respectively $1.261 \times 10^{5}$,

Table 2 Comparison of the average Nusselt number with those of Tian and Karayiannis [30] for $\mathrm{Ra}=1.58 \times 10^{9}$

\begin{tabular}{lccc}
\hline $\mathrm{Ri}$ & $\mathrm{Nu},[30]$ & $\mathrm{Nu}$, present work & Error (\%) \\
\hline Hot wall & 55.63 & 58.32 & 4.61 \\
Cold wall & 54.93 & 57.55 & 4.55 \\
\hline
\end{tabular}

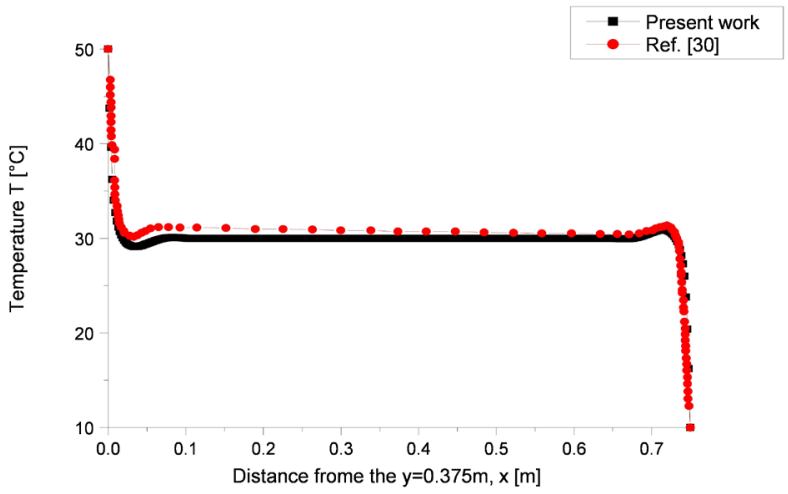

Fig. 2 Comparison of the present results with those of Tian and Karayiannis [30] for the temperature profile for $\mathrm{Ra}=1.58 \times 10^{9}$ 
$5.64 \times 10^{4}$ and $2.522 \times 10^{4}$. In the provided above parameter ranges, the focus of the present study is to investigate the effect of the exit position on the flow structure and mainly on the heat transfer characteristics. Results will be discussed in terms of the streamlines, isotherms and the computed local and average Nusselt number.

\subsection{Streamline and isotherm}

The typical streamlines are shown in Fig. 3. For the case of $\mathrm{Ri}=0.2$, the forced convection induces a counterclockwise big recirculation region that appears on the left side of the cavity and clockwise small vortices between the blocks on the right side of the cavity. When Richardson number is increased, naturel convection is dominant and the rotating vortices between the block disappear for $\mathrm{Ri}=5$. As for the comparison between the different geometries, we notice that whenever the exit opening is in the right side, there is a great friction between the air flow and the blocks which generates rotational cells. However, when the outlet position is switched to the left side of the cavity, the less contact between the air flow and the blocks is observed, which lead to a reduced rotation of the generated cells and absence of the cells for the cases ( $\mathrm{D}$ and $\mathrm{E}$ for $\mathrm{Ri}=1)$.

The distribution of the temperature for different geometries is shown in Fig. 4. Results shows that a zone of high temperature is located near the hot blocks for low values of $\mathrm{Ri}(\mathrm{Ri} \leq 1)$, and when the Richardson number increased $(\mathrm{Ri}>1)$ the large temperature gradients and the temperature distribution is located away from the hot blocks. As for the comparison between the different geometries, it is observed that the isotherms are deviating from the blocks to the outlet. For cases A and B they accentuate a heat lines as they go to the top of the right wall and to the right of the upper wall. For the case C, isotherms are directed to the center of the upper wall, and for cases $\mathrm{D}$ and $\mathrm{E}$ they are guided to the left of the upper wall and to the top of the left wall, respectively.

\subsection{Heat transfer}

Fig. 5 shows the influence of the outlet position and Richardson number on the local Nusselt number. For the vertical surfaces of the inlet flow (b-c, e-f and h-i surfaces). It is noticed that those cases have high local Nusselt number values compared to the horizontal surface's cases, and this is due to their friction with the cooling current. The local Nusselt number observed for the surfaces in contact with the inlet flow (a-b-c-d-e surfaces) for cases A and B was greater than that found in the cases C, D and E.

When comparing the results for different Richardson number, it is noted that the maximum Nusselt number could be observed at $\mathrm{Ri}=0.2$, and when the Richardson number increased further, the local Nusselt number is decreased.

Obtained results shown in Fig. 6 indicate that the average Nusselt number increases with decreasing Richardson number for all geometries. It can be noticed that the cases $\mathrm{A}$ and $\mathrm{B}$ are the best geometrical configurations for the cooling of blocks in comparison to $\mathrm{C}, \mathrm{D}$ and $\mathrm{E}$. The maximum Nusselt number could be obtained for the case A at $\mathrm{Ri}=0.2$.

\section{Conclusion}

A computational study of turbulent mixed convection in ventilated cavities is carried out to investigate the effect of different geometrical cases on the cooling of installed blocks at the cavity side. Conclusions from the obtained results in the range of Richardson number of 0.2 to 0.5 and five configurations based on the different outlet locations can be summarized as follows:

- The streamlines and isotherms have a strong dependence on Richardson's number. When forced convection increased recirculation cells between the blocks and thermal layer near the heated blocks become thin and concentrated. Also, the results of this investigation illustrated that the average Nusselt number at the heated blocks increases as the Richardson number decreases for all configurations. Generally, the highest cooling performance is achieved in the forced convection.

- The influence of outlet location is important for the design of the optimum geometry to achieve a better cooling effeciency. The analysis of the streamlines and isotherms, showed the generation of recirculation cells between the blocks which are enhanced for the configurations $\mathrm{A}, \mathrm{B}$, and $\mathrm{C}$. On the other hand, and from the results of the average Nusselt number, it is concluded that the geometrical case A followed by case B is best performing geometrical cases for the cooling of the blocks. 


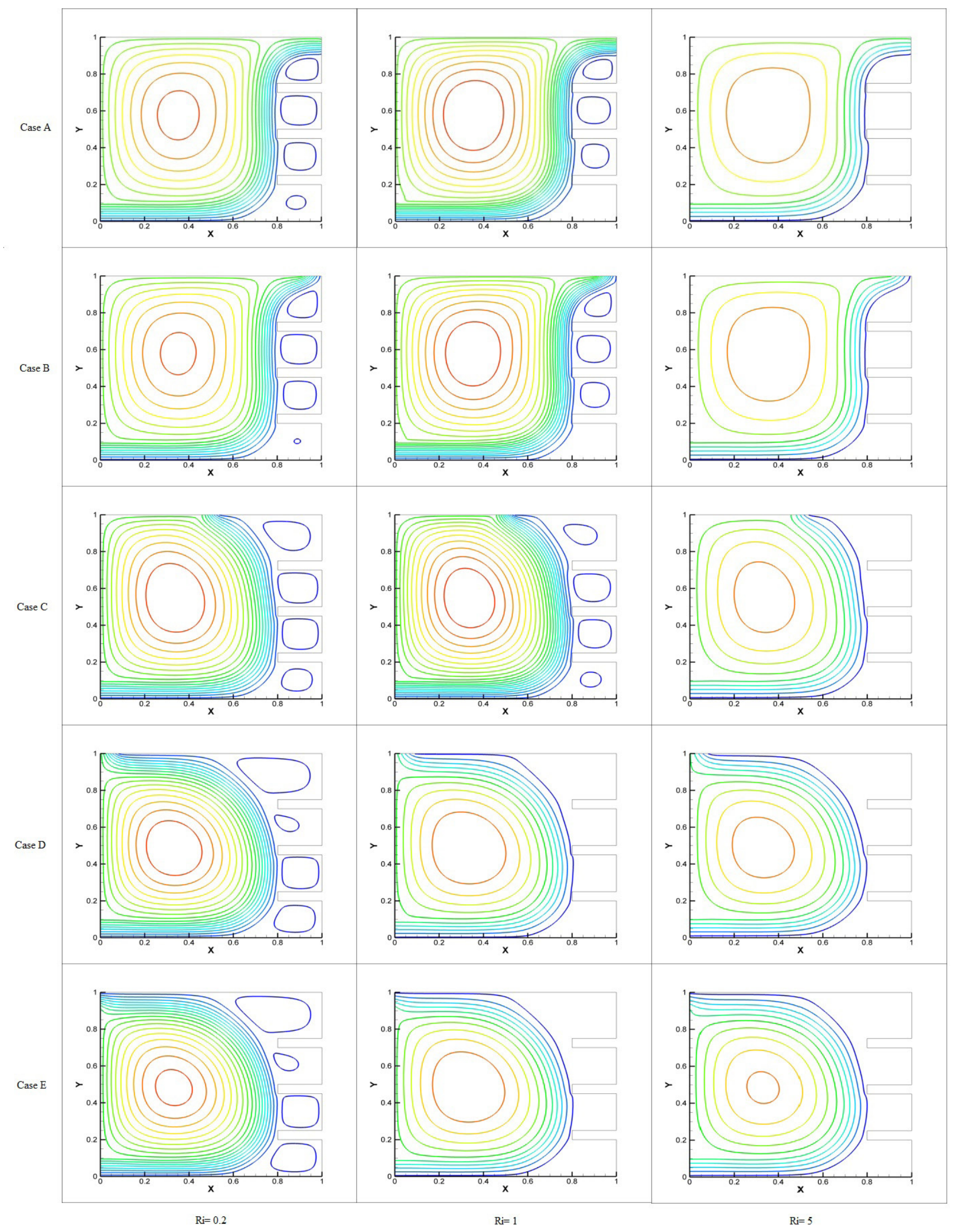

Fig. 3 Streamlines for different values of Richardson number Ri, while $\mathrm{Gr}=3.18 \times 10^{9}$ 


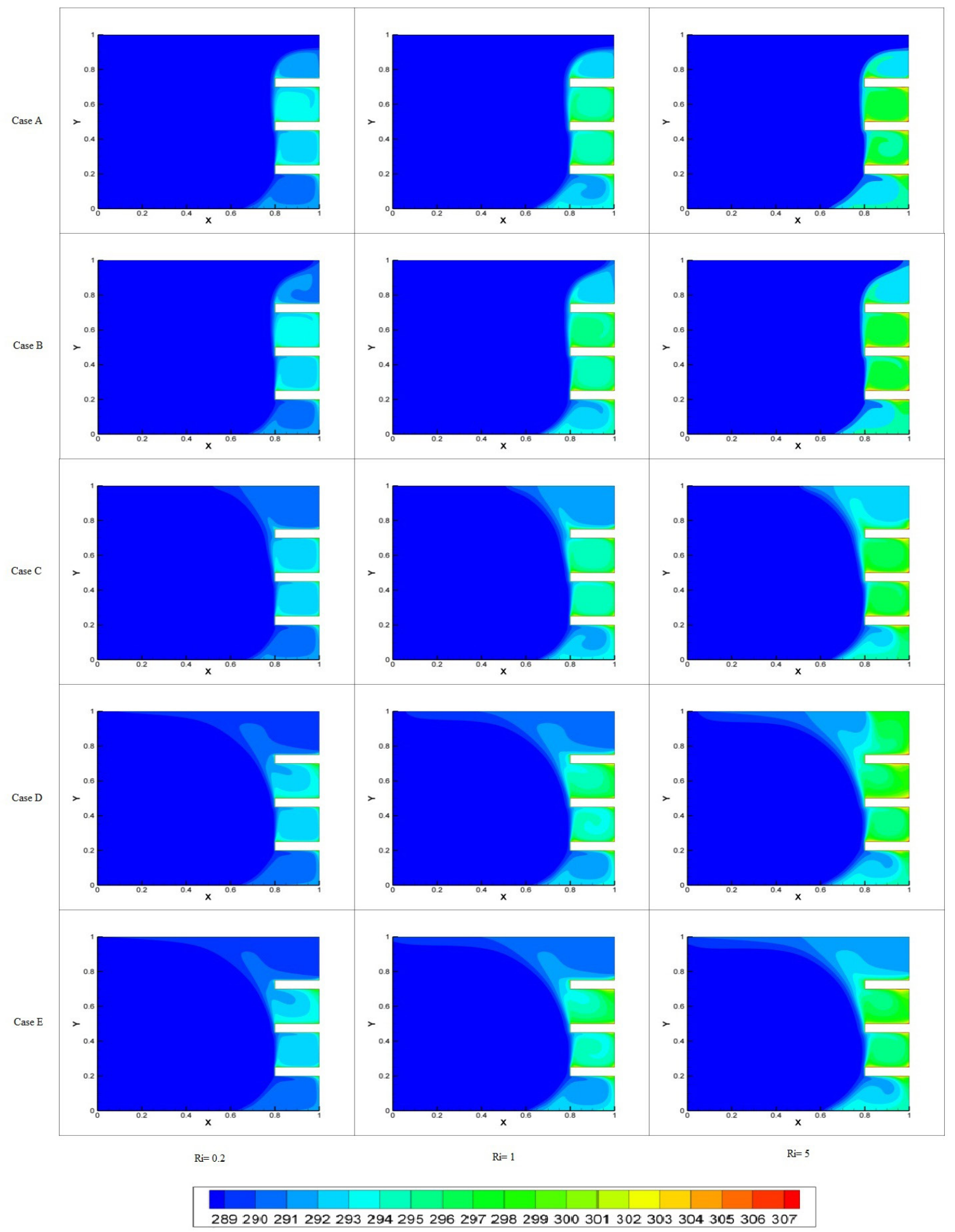

Fig. 4 Isotherms for different values of Richardson number $\mathrm{Ri}$, while $\mathrm{Gr}=3.18 \times 10^{9}$ 

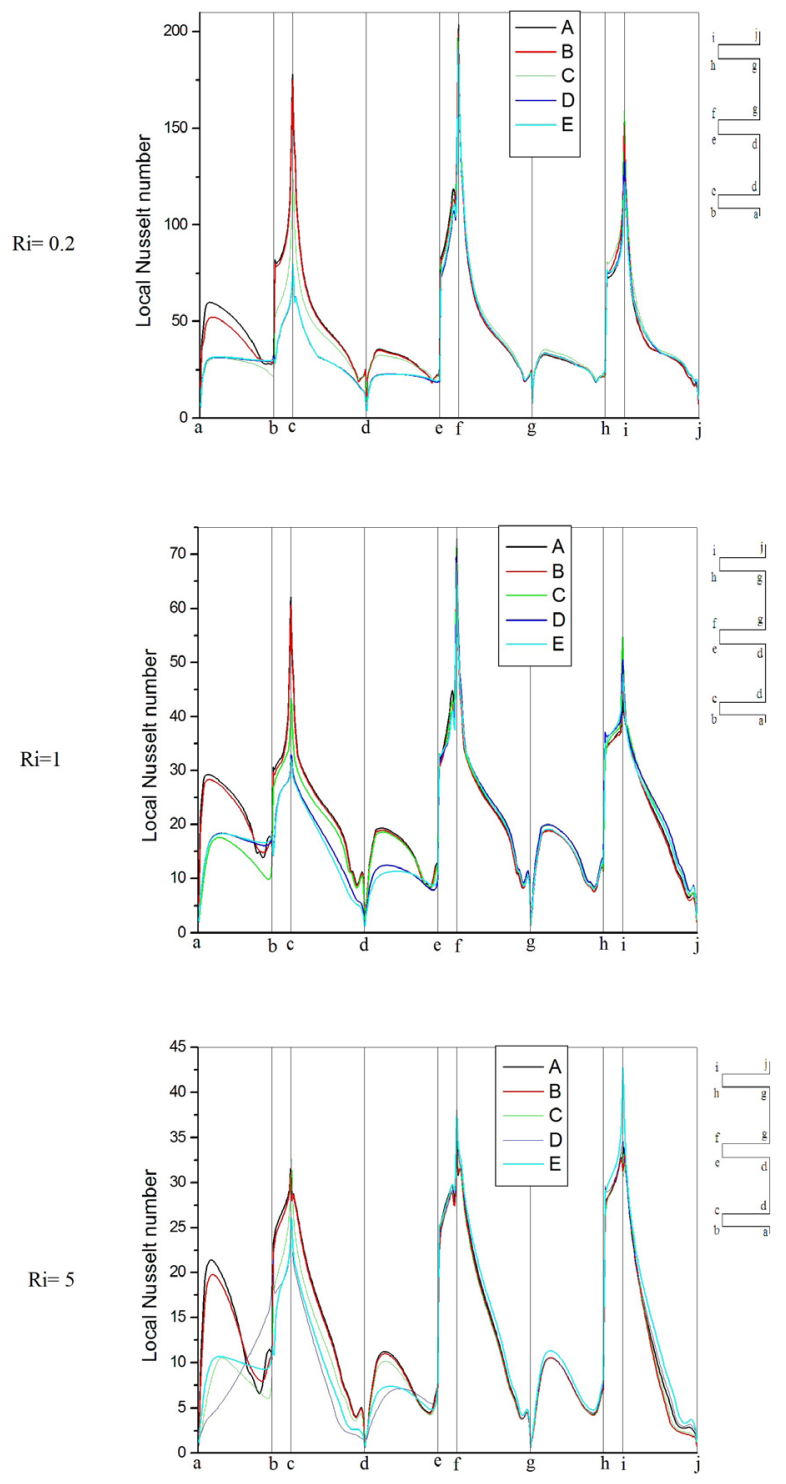

Fig. 5 Local Nusselt number on the blocks for different values of Richardson number

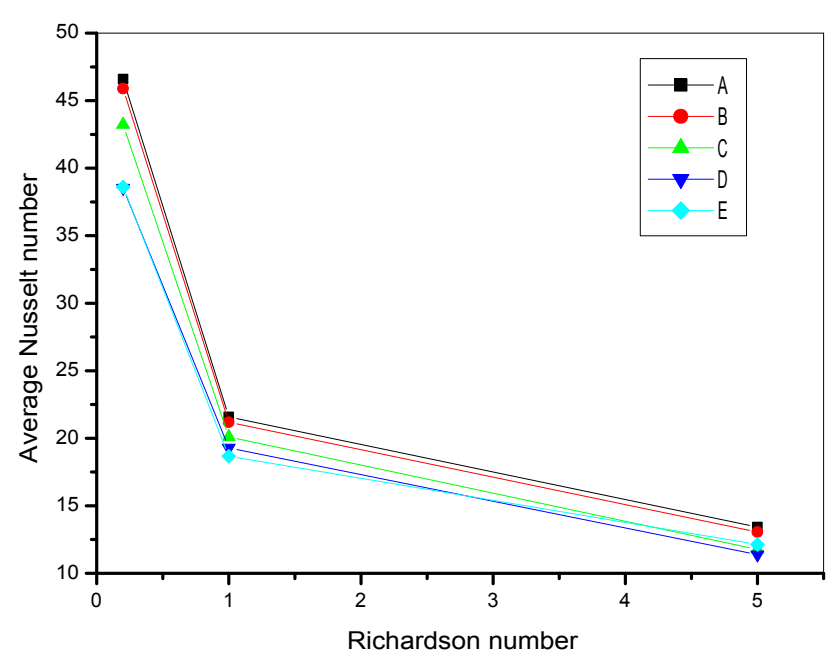

Fig. 6 Effect of the outlet position and Richardson number on the average Nusselt number

\section{Nomenclature}

$C_{1 \varepsilon}, C_{2 \varepsilon}$ constants of the turbulence model

$C_{3 \varepsilon}, C_{\mu}$ constants of the turbulence model

$d \quad$ blocks length, (m)

$d w \quad$ blocks thickness, (m)

$g$ gravitational acceleration, $\left(\mathrm{m} / \mathrm{s}^{2}\right)$

$G_{b} \quad$ generation of turbulent kinetic energy due to buoyancy, (J)

$G_{k} \quad$ generation of turbulent kinetic energy due to mean velocity gradient, $(\mathrm{J})$

Gr Grashof number

$h \quad$ inlet and outlet sections, (m)

$H \quad$ height of the enclosure, (m)

$k \quad$ turbulent kinetic energy, $\left(\mathrm{m}^{2} / \mathrm{s}^{2}\right)$

$n_{T} \quad$ unit vector tangential to the control volume surface

$\mathrm{Nu} \quad$ Nusselt number

$P \quad$ pressure, $(\mathrm{Pa})$

Pr Prandtl number

$\operatorname{Pr}_{t} \quad$ turbulent Prandtl number

$\mathrm{Ra} \quad$ Rayleigh number

Re Reynolds number

Ri Richardson number

$T$ Temperature, $(\mathrm{K})$

$t$ time, (s)

$u_{0} \quad$ inlet velocity $(\mathrm{m} / \mathrm{s})$

$u, v \quad$ velocity components, $(\mathrm{m} / \mathrm{s})$

$x, y \quad$ Cartesian coordinates, $(\mathrm{m})$

$w \quad$ dimensionless spacing between blocks, (m)

$\alpha \quad$ thermal diffusivity, $\left(\mathrm{m}^{2} / \mathrm{s}\right)$

$\beta \quad$ thermal expansion coefficient, $(1 / \mathrm{K})$

$\varepsilon \quad$ turbulent kinetic energy dissipation rate, $\left(\mathrm{m}^{2} / \mathrm{s}^{3}\right)$

$v \quad$ kinematic viscosity, $\left(\mathrm{m}^{2} / \mathrm{s}\right)$

$v t \quad$ turbulent eddy viscosity, $\left(\mathrm{m}^{2} / \mathrm{s}\right)$

$\tau_{\text {turb }} \quad$ turbulent shear stress

$\rho$ density of air $\left(\mathrm{kg} / \mathrm{m}^{3}\right)$

$\sigma_{k}, \sigma_{\varepsilon} \quad$ turbulent Prandtl numbers for $k$ and $\varepsilon$ 


\section{References}

[1] Kayne, A., Agarwal, R. K. "Computational Fluid Dynamics Modeling of Mixed Convection Flows in Buildings Enclosures", In: ASME 2013 7th International Conference on Energy Sustainability, Minneapolis, MN, USA, 2013, Article Number: V001T01A004.

https://doi.org/10.1115/ES2013-18026

[2] Amraoui, M. A., Aliane, K. "Three-dimensional Analysis of Air Flow in a Flat Plate Solar Collector", Periodica Polytechnica Mechanical Engineering, 62(2), pp. 126-135, 2018.

https://doi.org/10.3311/PPme.11255

[3] Horikiri, K., Yao, Y., Yao, J. "Numerical Simulation of Convective Airflow in an Empty Room", International Journal of Energy and Environment, 5(4), pp. 574-581, 2011. [online] Available at: https:// core.ac.uk/download/pdf/5223736.pdf [Accessed: 15 March 2020]

[4] Ghasemi, B. "Mixed Convection in a Rectangular Cavity with a Pulsating Heated Electronic Component", Numerical Heat Transfer, Part A: Applications: An International Journal of Computation and Methodology, 47(5), pp. 505-521, 2005. https://doi.org/10.1080/10407780590886278

[5] Radhakrishnan, T. V., Verma, A. K., Balaji, C., Venkateshan, S. P. "An experimental and numerical investigation of mixed convection from a heat generating element in a ventilated cavity", Experimental Thermal and Fluid Science, 32(2), pp. 502-520, 2007. https://doi.org/10.1016/j.expthermflusci.2007.06.001

[6] Bhoite, M. T., Narasimham, G. S. V. L. "Turbulent mixed convection in a shallow enclosure with a series of heat generating components", International Journal of Thermal Sciences, 48(5), pp. 948-963, 2009.

https://doi.org/10.1016/j.ijthermalsci.2008.08.010

[7] Cao, S. J., Meyers, J. "Influence of turbulent boundary conditions on RANS simulations of pollutant dispersion in mechanically ventilated enclosures with transitional slot Reynolds number", Building and Environment, 59, pp. 397-407, 2013.

https://doi.org/10.1016/j.buildenv.2012.09.004

[8] Harish, R., Venkatasubbaiah, K. "Numerical simulation of turbulent plume spread in ceiling vented enclosure", European Journal of Mechanics - B/Fluids, 42, pp. 142-158, 2013.

https://doi.org/10.1016/j.euromechflu.2013.06.001

[9] Beya, B. B., Lili, T. "Oscillatory double-diffusive mixed convection in a two-dimensional ventilated enclosure", International Journal of Heat and Mass Transfer, 50(23-24), pp. 4540-4553, 2007. https://doi.org/10.1016/j.ijheatmasstransfer.2007.03.027

[10] Zhao, F. Y., Liu, D., Tang, L., Ding, Y. L., Tang, G. F. "Direct and inverse mixed convections in an enclosure with ventilation ports", International Journal of Heat and Mass Transfer, 52(19-20), pp. 4400-4412, 2009. https://doi.org/10.1016/j.ijheatmasstransfer.2009.03.017

[11] Ajmera, S. K., Mathur, A. N. "Experimental investigation of mixed convection in multiple ventilated enclosure with discrete heat sources", Experimental Thermal and Fluid Science, 68, pp. 402-411, 2015. https://doi.org/10.1016/j.expthermflusci.2015.05.012
[12] Bhoite, M. T., Narasimham, G. S. V. L., Krishna Murthy, M. V. "Mixed convection in a shallow enclosure with a series of heat generating components", International Journal of Thermal Sciences, 44(2), pp. 121-135, 2005. https://doi.org/10.1016/j.ijthermalsci.2004.07.003

[13] Mamun, M. A. H., Rahman, M. M., Billah, M. M., Saidur, R. "A numerical study on the effect of a heated hollow cylinder on mixed convection in a ventilated cavity", International Communications in Heat and Mass Transfer, 37(9), pp. 1326-1334, 2010. https://doi.org/10.1016/j.icheatmasstransfer.2010.07.019

[14] Kalidasan, K., Velkennedy, R., Kanna, P. R. "Buoyancy enhanced natural convection inside the ventilated square enclosure with a partition and an overhanging transverse baffle", International Communications in Heat and Mass Transfer, 56, pp. 121-132, 2014. https://doi.org/10.1016/j.icheatmasstransfer.2014.06.007

[15] Xu, H., Xiao, R., Karimi, F., Yang, M., Zhang, Y. "Numerical study of double diffusive mixed convection around a heated cylinder in an enclosure", International Journal of Thermal Sciences, 78, pp. 169-181, 2014.

https://doi.org/10.1016/j.ijthermalsci.2013.12.016

[16] Tsay, Y. L., Cheng, J. C. "Analysis of convective heat transfer characteristics for a channel containing short multi-boards mounted with heat generating blocks", International Journal of Heat and Mass Transfer, 51(1-2), pp. 145-154, 2008.

https://doi.org/10.1016/j.ijheatmasstransfer.2007.04.006

[17] Doghmi, H., Abourida, B., Belarche, L., Sannad, M., Ouzaouit, M. "Numerical study of mixed convection inside a three-dimensional ventilated cavity in the presence of an isothermal heating block", International Journal of Heat and Technology, 36(2), pp. 447-456, 2018.

https://doi.org/10.18280/ijht.360209

[18] Costa, J. J., Oliveira, L. A., Blay, D. "Turbulent airflow in a room with a two-jet heating-ventilation system - a numerical parametric study", Energy and Buildings, 32(3), pp. 327-343, 2000. https://doi.org/10.1016/S0378-7788(00)00056-6

[19] Costa, J. J., Oliveira, L. A., Blay, D. "Test of several versions for the $k-\varepsilon$ type turbulence modelling of internal mixed convection flows", International Journal of Heat and Mass Transfer, 42(23), pp. 4391-4409, 1999. https://doi.org/10.1016/S0017-9310(99)00075-7

[20] Koufi, L., Younsi, Z., Cherif, Y., Naji. H. "Numerical investigation of turbulent mixed convection in an open cavity: Effect of inlet and outlet openings", International Journal of Thermal Sciences, 116, pp. 103-117, 2017. https://doi.org/10.1016/j.ijthermalsci.2017.02.007

[21] Ezzouhri, R., Joubert, P., Penot, F., Mergui, S. "Large Eddy simulation of turbulent mixed convection in a $3 \mathrm{D}$ ventilated cavity: Comparison with existing data", International Journal of Thermal Sciences, 48(11), pp. 2017-2024, 2009. https://doi.org/10.1016/j.ijthermalsci.2009.03.017 
[22] Ding, P., Wang, S., Chen, K. "Numerical study on turbulent mixed convection in a vertical plane channel using hybrid RANS/LES and LES models", Chinese Journal of Chemical Engineering, 28(1), pp. 1-8, 2020.

https://doi.org/10.1016/j.cjche.2019.04.007

[23] Huang, Y. Y., Yang, G., Wu, J. Y. "Large eddy simulation and experimental study of turbulent mixed convection inside a cavity with large Rayleigh number: Effect of buoyancy", Building and Environment, 151, pp. 268-279, 2019. https://doi.org/10.1016/j.buildenv.2019.01.041

[24] Barakos, G., Mitsoulis, E., Assimacopoulos, D. "Natural convection flow in a square cavity revisited: Laminar and turbulent models with wall functions", International Journal for Numerical Methods in Fluids, 18(7), pp. 695-719, 1994. https://doi.org/10.1002/fld.1650180705

[25] Mataoui, A., Schiestel, R., Salem, A. "Study of the oscillatory regime of a turbulent plane jet impinging in a rectangular cavity", Applied Mathematical Modelling, 27(2), pp. 89-114, 2003. https://doi.org/10.1016/S0307-904X(02)00050-1

[26] Serrano-Arellano, J., Xamán, J, Álvarez, G. "Optimum ventilation based on the ventilation effectiveness for temperature and $\mathrm{CO}_{2}$ distribution in ventilated cavities", International Journal of Heat and Mass Transfer, 62, pp. 9-21, 2013. https://doi.org/10.1016/j.ijheatmasstransfer.2013.02.051

[27] Mohseni, M., Bazargan, M. "Entropy generation in turbulent mixed convection heat transfer to highly variable property pipe flow of supercritical fluids", Energy Conversion and Management, 87, pp. 552-558, 2014. https://doi.org/10.1016/j.enconman.2014.07.013

[28] Serrano-Arellano, J., Gijón-Rivera, M., Riesco-Ávila, J. M., Xamán, J., Álvarez, G. "Numerical investigation of transient heat and mass transfer by natural convection in a ventilated cavity: Outlet air gap located close to heat source", International Journal of Heat and Mass Transfer, 76, pp. 268-278, 2014. https://doi.org/10.1016/j.ijheatmasstransfer.2014.04.055
[29] Pulat, E., Ersan, H. A. "Numerical simulation of turbulent airflow in a ventilated room: Inlet turbulence parameters and solution multiplicity", Energy and Buildings, 93, pp. 227-235, 2015. https://doi.org/10.1016/j.enbuild.2015.01.067

[30] Tian, Y. S., Karayiannis, T. G. "Low turbulence natural convection in an air-filled square cavity: Part I: the thermal and fluid flow fields", International Journal of Heat and Mass Transfer, 43(6), pp. 849-866, 2000. https://doi.org/10.1016/S0017-9310(99)00199-4

[31] Serrano-Arellano, J., Belman-Flores, J. M., Hernández-Pérez, I., Aguilar-Castro, K. M., Macías-Melo, E. V., Elizalde-Blancas, F., Riesco-Ávila, J. M., García-Rodríguez, F. J. "Numerical Study of the Distribution of Temperatures and Relative Humidity in a Ventilated Room Located in Warm Weather", Computer Modeling in Engineering \& Sciences, 123(2), pp. 571-602, 2020. https://doi.org/10.32604/cmes.2020.08677

[32] Kriraa, M., Souhar, K., Achemlal, D., Ait Yassine, Y., Farchi, A. "Fluid Flow and Convective Heat Transfer in a Water Chemical Condenser", Fluid Dynamics \& Materials Processing, 16(2), pp. 199-209, 2020. https://doi.org/10.32604/fdmp.2020.07986

[33] ANSYS, Inc. "ANSYS FLUENT 12.0 Theory Guide", ANSYS, Inc., Canonsburg, PA, USA, 2009.

[34] Press, W. H., Teukolsky, S. A., Vetterling, W. T., Flannery, B. P. "Numerical Recipes in Fortran 77", Cambridge University Press, Cambridge, UK, 1992.

[35] Mokeddem, M., Laidoudi, H., Makinde, O. D., Bouzit, M. "3D Simulation of Incompressible Poiseuille Flow through $180^{\circ}$ Curved Duct of Square Cross-section under Effect of Thermal Buoyancy", Periodica Polytechnica Mechanical Engineering, 63(4), pp. 257-269, 2019. https://doi.org/10.3311/PPme.12773 